\title{
Seasonal Variation of Psoriasis and Its Impact in the Therapeutic Management: A Retrospective Study on Chinese Patients
}

\author{
Xuanwei Zheng ${ }^{1-3, *}$ \\ Qiaolin Wang (D) ${ }^{1-3, *}$ \\ Yan Luo ${ }^{1-3}$ \\ Wenhua $\mathrm{Lu}^{1-3}$ \\ Liping Jin ${ }^{1-3}$ \\ Menglin Chen ${ }^{1-3}$ \\ Wu Zhu (D) ${ }^{1-3}$ \\ Yehong Kuang ${ }^{1-3}$ \\ 'Department of Dermatology, Xiangya \\ Hospital, Central South University, \\ Changsha, 410008, People's Republic of \\ China; ${ }^{2}$ National Clinical Research \\ Center for Geriatric Disorders (Xiangya \\ Hospital), Changsha, 4I0008, People's \\ Republic of China; ${ }^{3}$ Hunan Engineering \\ Research Center of Skin Health and \\ Disease, Hunan Key Laboratory of Skin \\ Cancer and Psoriasis (Xiangya Hospital), \\ Changsha, 410008, People's Republic of \\ China
}

*These authors contributed equally to this work
Correspondence: Wu Zhu; Yehong Kuang Xiangya Hospital, Central South University, 87 Xiangya Road, Changsha, Hunan, People's Republic of China

Tel +86-I33 I9509308; +86-I3574I IIII02

Email zhuwu70@hotmail.com;

yh_927@I26.com
Background: The seasonal patterns of psoriasis have been observed in previous studies. However, no published data indicated the risk factors associated with the seasonal variation. Purpose: This study aimed to investigate potentially related factors associated with seasonal pattern of psoriasis and provide possible implications for alleviating psoriasis in clinical practice.

Patients and Methods: The retrospective study was conducted in Chinese patients with psoriasis. Demographic and clinical information were collected. Multivariable logistic regression analyses (calculating adjusted odds ratios [AORs]) were used to analyze data.

Results: We continually enrolled 2270 patients (1496 males and 774 females) with psoriasis based on inclusion criteria. Disease duration (AOR=1.06, 95\% CI: 1.05-1.07), hyperlipidemia (AOR=1.77, 95\% CI: 1.06-2.98) and smoking (AOR $=1.40,95 \%$ CI: $1.17-1.68$ ) were significantly associated with severe psoriasis in autumn/winter. Age (AOR $=0.98,95 \%$ CI:0.97-0.99) and occupations with more sunlight exposure (AOR $=0.78,95 \%$ CI: $0.61-0.99)$ were negatively associated with the seasonal aggravation. Subgroup analysis showed that occupations with more sunlight exposure $(\mathrm{AOR}=0.64,95 \% \mathrm{CI}$ : $0.43-0.94)$ were protective factors only in late-onset psoriasis but not early-onset, while smoking ( $\mathrm{AOR}=1.39,95 \% \mathrm{CI}$ : 1.11-1.74) was risk factor in the early-onset psoriasis.

Conclusion: Psoriatic patients who had occupation with more sunlight exposure were less likely to report aggravation of psoriasis in autumn/winter. On the contrary, smoking and hyperlipidemia were positively associated with the seasonal aggravation. Additional prospective study is needed to identify the causality.

Keywords: psoriasis, seasonal variation, weather, occupational exposure, ultraviolet, smoking

\section{Introduction}

Psoriasis is an auto-inflammatory skin disease characterized by red or silver scaly plaques, typically distributing the elbows, knees, and scalp. The prevalence of psoriasis ranges from $0.09 \%$ to $11.4 \%$ globally, ${ }^{1,2}$ the prevalence is between $0.17 \%$ and $0.59 \%$ in China. ${ }^{3,4}$ Though the pathophysiology of psoriasis remains unclarified, it is identified that psoriasis can be induced by genetic and environmental factors. ${ }^{5,6}$ It is known that infections, ${ }^{6}$ psychological stress, ${ }^{6}$ diet, ${ }^{6,7}$ medication, ${ }^{6,7}$ smoking, ${ }^{6-10}$ alcohol drinking, ${ }^{6,9,11}$ so as the cold and dry weather, ${ }^{12}$ could trigger the flare-ups of psoriasis. Systemic inflammation together with demographics ${ }^{13}$ could drastically influence the prescription of treatment and therapeutic response by increasing psoriasis-related 
comorbidities burden (ie, cardiovascular, ${ }^{14}$ respiratory ${ }^{15}$ or hepatic disease ${ }^{16}$ ). Previous studies confirmed that psoriasis conditions vary with the season, and severe psoriasis were more likely to happen in cold season, such as autumn or/and winter. ${ }^{12}$ The seasonal patterns of psoriasis have been commonly observed in clinical practice. Many studies with different designs have investigated the seasonality of psoriasis. ${ }^{12,17-20}$ However, to our knowledge, no published research has investigated the risk factors associated with the seasonal variation.

Therefore, the purpose of the study is to investigate the seasonal variation of psoriasis conditions and its potential related factors in Chinese patients with psoriasis, and provide possible implications for alleviating psoriasis in clinical practice.

\section{Patients and Methods}

\section{Study Design and Participants}

This was a single center retrospective study in Chinese patients with psoriasis. Patients initially admitted to the dermatology department of Xiangya Hospital from Jan 2016 to Sep 2019 were consecutively enrolled if they met all the following inclusion criteria: 1 ) age $\geq 18$ years; 2) diagnosis of plaque psoriasis was confirmed by two or more experienced dermatologists; 3) disease duration $\geq$ 1 year. Cases with missing data (including demographic and clinical information) were excluded from the study. All participants signed the consent form and were informed about the purpose of the study. The study followed the Declaration of Helsinki and was approved by the institutional research ethics boards of Xiangya Hospital.

\section{Data Collection}

Information included demographic characteristics (age, sex, education level, occupation, cigarette smoking and alcohol drinking) and clinical characteristics (psoriasis-related information and comorbidities) were collected through face-toface interview. Deterioration of psoriasis condition was the primary outcome of the study, measured by the Global Rating of Change (GRC). We defined deteriorated psoriasis condition as the increased erythema, infiltration, desquamation, and symptom of itching. Comorbidities were determined by laboratory tests, self-report and medications usage. Hyperlipidemia was diagnosed according to triglycerides $\geq 2.3 \mathrm{mmol} / \mathrm{L}$, low-density lipoprotein cholesterol $\geq 4.1 \mathrm{mmol} / \mathrm{L}$, high-density lipoprotein cholesterol $\leq 1.0 \mathrm{mmol} / \mathrm{L}$ or total cholesterol $\geq 6.2 \mathrm{mmol} / \mathrm{L}$ based on the Chinese Guideline for the Management of Hyperlipidemia in Adults in 2016. ${ }^{21}$ Hypertension was diagnosed according to self-report and the Chinese Guidelines for the Management of Hypertension. ${ }^{22}$ Diabetes was diagnosed according to self-report and the 1999 WHO diagnostic criteria. Height, weight, waistline and hipline were measured in a standard way. Body Mass Index (BMI) was calculated as weight $(\mathrm{kg}) /$ height squared (m2). Waist-to-Height Ratio (WHR) was calculated as waistline $(\mathrm{cm}) /$ hipline $(\mathrm{cm})$. Occupations were grouped by reviewing of job descriptions into categories of occupations with more sunlight exposure or not. Participants who engaged in agriculture, forestry, stockbreeding, aquaculture or construction were defined as individuals with more sunlight exposure. Participants who work indoor, or being a full-time student or retired were defined as individuals with less sunlight exposure. We categorized patients who developed psoriatic lesions prior to 40 years old as the early onset group, and after 40 as the late onset one.

\section{Statistical Analysis}

Continuous variables with normal distribution were expressed as mean \pm standard deviation (SD), and compared with analysis of variance (ANOVA). Continuous data with skewed distribution were presented as median (interquartile range, IQR), and compared with MannWhitney rank sum test. Categorical variables were summarized as counts (percentages) and compared using the chi-square test or Fisher's exact test. Multivariable logistic regression analyses were employed to analyze the data. Variables having $P$ value $<0.1$ on the univariate analysis were included in multivariable analysis. Odds ratio (OR) and $95 \%$ confidence interval were used to present the effect size of the associations. $P$ value less than 0.05 was considered statistically significant. The data were analyzed with SPSS 23 (IBM, SPSS Statistics 23).

\section{Results}

This study included 2582 patients under the inclusion criteria. Three hundred and twelve cases were excluded for incomplete data. Table 1 summarized the demographic and clinical characteristics of 2270 participants (1496 males and 774 females) divided into two groups according to whether the patients have aggravated psoriasis conditions during autumn or winter. A total of $53.2 \%$ reported the seasonal pattern of disease. The mean age of all participants was $42.1 \pm 14.1$ years, and the mean disease 
Table I Characteristics of the Patients by Different Psoriasis Condition in Winter/Autumn

\begin{tabular}{|c|c|c|c|}
\hline \multirow[t]{2}{*}{ Characteristics } & \multicolumn{3}{|c|}{$\begin{array}{l}\text { Psoriasis Aggravated in } \\
\text { Winter/Autumn }\end{array}$} \\
\hline & $\begin{array}{c}\text { Yes } \\
(n=\mid 207)\end{array}$ & $\begin{array}{c}\text { No } \\
(n=1063)\end{array}$ & $\mathbf{P}$ \\
\hline Age (mean $\pm S D)$ & $41.2 \pm 13.3$ & $43.3 \pm 14.8$ & 0.001 \\
\hline Female, $n(\%)$ & $410(34.0)$ & $365(34.3)$ & 0.854 \\
\hline $\begin{array}{l}\text { Education level, n (\%) } \\
\text { Primary } \\
\text { Secondary } \\
\text { Higher }\end{array}$ & $\begin{array}{l}128(10.6) \\
615(50.9) \\
464(38.5)\end{array}$ & $\begin{array}{ll}149 & (14.0) \\
56 \mid & (52.8) \\
353 & (33.2)\end{array}$ & 0.007 \\
\hline Age at onset (mean $\pm S D$ ) & $29.6 \pm 12.8$ & $35.1 \pm 14.9$ & $<0.001$ \\
\hline Disease duration (mean $\pm \mathrm{SD}$ ) & $11.5 \pm 8.9$ & $8.2 \pm 8.3$ & $<0.001$ \\
\hline BMI $\left(\mathrm{kg} / \mathrm{m}^{2}\right)($ mean $\pm \mathrm{SD})$ & $23.5 \pm 3.6$ & $23.9 \pm 3.8$ & 0.009 \\
\hline WHR $($ mean $\pm S D)$ & $0.89 \pm 0.07$ & $0.90 \pm 0.08$ & 0.137 \\
\hline $\begin{array}{l}\text { Occupation with more sunlight } \\
\text { exposure }\end{array}$ & $193(16.0)$ & $217(20.4)$ & 0.006 \\
\hline Comorbidities, n (\%) & & & \\
\hline Hypertension & $87(7.2)$ & $99(9.3)$ & 0.068 \\
\hline Hyperlipidemia & $44(3.6)$ & $27(2.5)$ & 0.131 \\
\hline Diabetes & $55(4.6)$ & $51(4.8)$ & 0.786 \\
\hline Smoking & $447(37.0)$ & $354(33.3)$ & 0.063 \\
\hline Alcohol drinking & $4 I 2(34.1)$ & $389(36.6)$ & 0.231 \\
\hline
\end{tabular}

Note: $P$ value by univariate logistic regression model.

Abbreviations: BMI, body mass index; WHR, waist-to-height ratio.

duration was $10.0 \pm 8.8$ years. Age, educational level, disease duration, BMI, smoking and occupations with more sunlight exposure were significantly different between the two groups $(P<0.05)$. No obvious differences were found in sex, WHR, comorbidities (hypertension, hyperlipidemia and diabetes) and alcohol drinking $(P>0.05)$.

To further examine the associations, we performed a series of logistic regression modeling with adjustments. As shown in Table 2, age (AOR $=0.98 ; 95 \% \mathrm{CI}$ : $0.97-0.99 ; P<0.001)$ and occupation with more sunlight exposure $(\mathrm{AOR}=0.78 ; 95 \%$ CI: $0.61-0.99 ; \quad P=0.039)$ were negatively associated with severe symptoms in autumn or winter. Disease duration (AOR $=1.06 ; 95 \%$ CI: $1.05-1.07 ; P<0.001$ ), hyperlipidemia $(\mathrm{AOR}=1.77$; 95\% CI: $1.06-2.98 ; \quad P=0.030)$ and smoking $(\mathrm{AOR}=1.40 ; 95 \% \mathrm{CI}: 1.17-1.68 ; P<0.001)$ were positively associated with the aggravation of psoriasis in winter.
Subgroup analyses for both early and late-onset psoriasis were shown in Table 3. The association remained consistent in general. Smoking was positively associated with psoriasis aggravation in autumn/winter for earlyonset psoriasis $\quad(\mathrm{AOR}=1.39 ; \quad 95 \% \quad \mathrm{CI}: \quad 1.11-1.74$; $P=0.004$ ), age (AOR $=0.97 ; 95 \%$ CI: $0.95-0.99 ; P=0.009$ ) and occupation with more sunlight exposure $(\mathrm{AOR}=0.64$; 95\% CI: $0.43-0.94 ; P=0.024)$ were negatively associated with aggravated conditions in autumn/winter for late-onset type of psoriasis.

\section{Discussion}

Our study indicated that $53.2 \%$ patients with psoriasis had aggravation of disease conditions in fall/winter. The seasonality peaking of psoriasis has been observed in clinical practice, which is verified by the significant seasonal variation in dermatologic office visits. ${ }^{12}$ Observational investigations, based on Google Trends datasets, showed that the public interest in seeking psoriasis-related information displayed a seasonal trend, with the highest interest appeared in late winter and early spring. ${ }^{17,18}$ The trend of online researches also implied the association between the psoriasis flare and the weather.

Low humidity and lack of ultraviolet (UV) radiation exposure were mainly blamed for the aggravation of the psoriasis in fall/winter. ${ }^{19,20}$ It has been known for centuries that sunlight can improve many inflammatory skin conditions, including psoriasis. UV radiation has been generally used in treating psoriasis for decades. Wide variation in the prevalence of psoriasis among populations could be attributed to the regional disparity of UV exposure. ${ }^{23}$ Low temperature makes heavy clothing necessary, thus leading to the deficiency of UV exposure. The mechanisms of UV in clearing psoriasis as follows. First, UV radiation is the main source of cutaneous vitamin D production. Significant associations between the low serum vitamin D level and psoriasis were found. ${ }^{24}$ Low level of vitamin D cannot prevent skin lesions from inhibiting the proliferation and inducing differentiation of keratinocyte. ${ }^{25,26}$ Second, UV suppresses the immune response by inhibiting Th17/IL-23 axis $^{27,28}$ and type 1 T-cell pathway, ${ }^{29-31}$ inducing T-cell apoptosis, ${ }^{32,33}$ followed by normalization of epidermal hyperplasia in vivo. ${ }^{34,35}$ In addition, UV contributes to apoptosis in lesional epidermis, especially the keratinocytes. ${ }^{36,37}$ Though the improvement of skin lesions was mainly related to sun exposure, the majority of psoriasis cases reported relief in summer and exacerbation in winter, few presented worse conditions due to photosensitivity. ${ }^{19}$ The relationship between skin and UV is complexed. Photoadaptation is a protective 
Table 2 Comparison of Both Psoriasis Condition in Winter/Autumn

\begin{tabular}{|c|c|c|c|c|}
\hline \multirow[t]{3}{*}{ Item } & \multicolumn{4}{|c|}{ Psoriasis Aggravated in Winter/Autumn } \\
\hline & \multirow{2}{*}{$\begin{array}{l}\text { No } \\
\text { OR }\end{array}$} & \multicolumn{3}{|c|}{ Yes } \\
\hline & & OR $(95 \% \mathrm{CI})$ & AOR $(95 \% \mathrm{Cl})^{a}$ & $\mathbf{P}$ \\
\hline Age & 1 & $0.99(0.98,0.99)$ & $0.98(0.97,0.99)$ & $<0.001$ \\
\hline Female & I & $0.98(0.83,1.17)$ & $0.93(0.75,1.16)$ & 0.516 \\
\hline Disease duration & I & $1.05(1.04,1.06)$ & $1.06(1.05,1.07)$ & $<0.001$ \\
\hline BMI $\left(\mathrm{kg} / \mathrm{m}^{2}\right)$ & I & $0.97(0.95,0.99)$ & $0.98(0.96,1.00)$ & 0.127 \\
\hline Occupation with more sunlight exposure & 1 & $0.74(0.60,0.92)$ & $0.78(0.61,0.99)$ & 0.039 \\
\hline \multicolumn{5}{|l|}{ Comorbidities } \\
\hline Hypertension & I & $0.76(0.56,1.02)$ & $0.90(0.64,1.26)$ & 0.536 \\
\hline Hyperlipidemia & I & $1.45(0.89,2.36)$ & $1.77(1.06,2.98)$ & 0.030 \\
\hline Diabetes & 1 & $0.95(0.64,1.40)$ & $\mathrm{I} .18(0.77, \mathrm{I} .8 \mathrm{I})$ & 0.461 \\
\hline Smoking & I & I.I8 $(0.99,1.40)$ & $1.40(1.17,1.68)$ & $<0.001$ \\
\hline Alcohol drinking & I & $0.90(0.76,1.07)$ & $0.93(0.76,1.12)$ & 0.426 \\
\hline
\end{tabular}

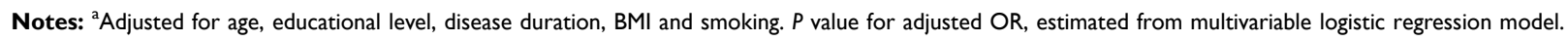
Abbreviations: OR, unadjusted odds ratio; $\mathrm{AOR}$, adjusted odds ratio; $\mathrm{Cl}$, confidence interval; $\mathrm{BMI}$, body mass index.

mechanism that the skin damage of the response to exposure to UV reduces after repeated exposures, which was verified in phototherapy for psoriasis. ${ }^{38}$ The melatonin, a hormone connected with light (seasonality and circadian rhythm), was found to have utility of maintaining skin homeostasis by suppressing of UV-induced photodamage. ${ }^{39}$ Exposure to low humidity and low temperature could cause skin hydration decreasing. ${ }^{40,41}$ The seasonal variation of skin hydration was also confirmed by Raman spectra in healthy skin. $^{42}$ Low environmental humidity causes the impairment of the skin

Table 3 Subgroup Analyses by Both Early and Late-Onset Psoriasis

\begin{tabular}{|c|c|c|c|c|}
\hline \multirow[t]{2}{*}{ Variables } & \multicolumn{2}{|c|}{ Early-Onset Psoriasis } & \multicolumn{2}{|c|}{ Late-Onset Psoriasis } \\
\hline & AOR $(95 \% \mathrm{CI})^{a}$ & $\boldsymbol{P}$ & $\operatorname{AOR}(95 \% \mathrm{Cl})^{a}$ & $P$ \\
\hline Age & $0.99(0.97,1.00)$ & 0.107 & $0.97(0.95,0.99)$ & 0.009 \\
\hline Female & $0.95(0.73,1.23)$ & 0.696 & $0.91(0.59,1.41)$ & 0.682 \\
\hline Disease duration & $1.06(1.04,1.07)$ & $<0.001$ & $1.08(1.05,1.12)$ & $<0.001$ \\
\hline BMI $\left(\mathrm{kg} / \mathrm{m}^{2}\right)$ & $0.98(0.95,1.00)$ & 0.099 & $0.99(0.94,1.03)$ & 0.557 \\
\hline $\begin{array}{l}\text { Occupation with more } \\
\text { sunlight exposure }\end{array}$ & $0.88(0.64,1.20)$ & 0.403 & $0.64(0.43,0.94)$ & 0.024 \\
\hline \multicolumn{5}{|l|}{ Comorbidities } \\
\hline Hypertension & $1.06(0.62,1.79)$ & 0.841 & $0.80(0.50,1.28)$ & 0.351 \\
\hline Hyperlipidemia & I.70 $(0.78,3.68)$ & 0.182 & $1.79(0.88,3.64)$ & 0.109 \\
\hline Diabetes & I. $16(0.55,2.48)$ & 0.697 & $1.18(0.69,2.01)$ & $0.54 I$ \\
\hline Smoking & $1.39(1.11,1.74)$ & 0.004 & $1.34(0.96,1.86)$ & 0.087 \\
\hline Alcohol drinking & $0.87(0.69,1.10)$ & 0.243 & I.0I $(0.71,1.42)$ & 0.965 \\
\hline
\end{tabular}

Notes: ${ }^{a}$ Adjusted for age, educational level, disease duration, BMI and smoking. $P$ value for adjusted OR, estimated from multivariable logistic regression model. Abbreviations: $\mathrm{AOR}$, adjusted odds ratio; $\mathrm{Cl}$, confidence interval; $\mathrm{BMI}$, body mass index. 
barrier function and the increased susceptibility towards mechanical stress, resulting in marked epidermal hyperplasia. ${ }^{43}$ However, the damp environment is also confirmed as the risk factor in the aggravation of psoriasis. ${ }^{7}$ The ideal humidity level in patients with psoriasis remains unknown.

Actually, not all patients had the seasonal patterns of psoriasis. Our data showed $46.8 \%$ patients did not report the aggravation of psoriasis in autumn/winter. We explored the seasonal variation of psoriasis and its potential risk factors for the first time. Occupations with more sunlight exposure seemed to be the protective factor to psoriasis aggravation in cold weather, especially for late-onset psoriasis, which could be explained as the sun exposure during the cold and dry seasons alleviates the skin conditions. In view of the efficacy of ultraviolet irradiation on psoriatic lesions, phototherapy and climatotherapy (such as Dead Sea climatotherapy) are generally used as therapies for psoriasis. However, the further study between the natural UV exposure and disease severity in psoriasis is warranted.

Pascoe and Kimball estimated the seasonal variation in psoriasis by using Physician's Global Assessment (PGA) scales and disease clearing level. ${ }^{20}$ Different from the study, our data showed that age showed a negative relationship with the seasonal aggravation, contrary to disease duration. Different evaluations of disease severity make the difference, on account of the discordance between objective measurement and patient self-report. ${ }^{44}$ Still, the non-sampling error cannot be avoided if the study based on patient-reported outcomes.

Smoking, ${ }^{6-10}$ alcohol consumption ${ }^{6,9,10}$ and metabolic syndrome $^{9,45}$ (obesity, hypertension, hyperlipidemia, diabetes) are recognized as risk factors for severe psoriasis. Our study had similar results, and smoking showed bigger effects on disease conditions for early-onset psoriasis in fall/winter. The positive association of smoking, hyperlipidemia with psoriasis aggravation emphasizes the significance of lifestyle interventions in psoriasis treatment. Smoking cessation and diet management should be strongly recommended by physicians. To control the disease activity and itching symptom, the necessity of longterm therapy needs to be emphasized since seasonality and circadian rhythm perturbations deeply influence psoriasis severity and flare-ups. ${ }^{46,47}$

This study has some limitations. First, all data were collected from a single center, causal inferences need to be discriminate by prospective studies. Second, a part of variables was collected based on patient self-reports, which leads to inevitable response bias and recall bias. Third, in our data analysis, major potential confounders have been controlled, however, the unknown and unmeasured factors cannot be adjusted.

\section{Conclusions}

In conclusion, our study indicated that occupations with more sunlight exposure might prevent patients from aggravation of psoriasis in the cold and dry season. In contrast, smoking and hyperlipidemia were positively associated with the seasonal aggravation. Causality has to be identified by prospective studies. Lifestyle changes, such as appropriate natural UV exposure through outdoor activities and smoking cessation, are essential for alleviating psoriasis.

\section{Data Sharing Statement}

The data used in this study is unpublished, but it can be obtained through contacting first authors' emails (Qiaolin Wang, email: wangqiaolin701@163.com).

\section{Ethics Approval}

This study was approved by the institutional research ethics boards of Xiangya Hospital, Central South University (Changsha, China).

\section{Consent for Publication}

All authors have agreed to submit this article to the journal and to be accountable for all aspects of the work.

\section{Acknowledgments}

The authors would like to thank Dr Tingyin Chen (Xiangya Hospital, Central South University) for his contribution to the data collection.

\section{Funding}

This work was supported by the key project of the National Science Foundation (81430075, 81830096), National Natural Science Foundation of China (81573049, 81974479, 81773329), Key R \& D Program of Hunan Province (2018SK2082), National key R \& D program (2018YFC0117004).

\section{Disclosure}

The authors report no conflicts of interest in this work. 


\section{References}

1. Gibbs S. Skin disease and socioeconomic conditions in rural Africa: Tanzania. Int J Dermatol. 1996;35(9):633-639. doi:10.1111/j.13654362.1996.tb03687.x

2. Danielsen K, Olsen AO, Wilsgaard T, Furberg AS. Is the prevalence of psoriasis increasing? A 30-year follow-up of a population-based cohort. Br J Dermatol. 2013;168(6):1303-1310. doi:10.1111/ bjd. 12230

3. Shao CG, Zhang GW, Wang GC. Distribution of psoriasis in China: a nationwide screening. Proc Chin Acad Med Sci Peking Union Med Coll. 1987;2(2):59-65.

4. Ding X, Wang T, Shen Y, et al. Prevalence of psoriasis in China: a population-based study in six cities. Eur $J$ Dermatol. 2012;22 (5):663-667. doi:10.1684/ejd.2012.1802

5. Nestle FO, Kaplan DH, Barker J. Psoriasis. N Engl J Med. 2009;361 (5):496-509. doi:10.1056/NEJMra0804595

6. Zeng J, Luo S, Huang Y, Lu Q. Critical role of environmental factors in the pathogenesis of psoriasis. J Dermatol. 2017;448(8):863-872. doi:10.1111/1346-8138.13806

7. Wei S, Gao M, Zhang X, Yang S. [Study of the association between HLA-DQA1 alleles and environmental factors in psoriasis]. Zhonghua Liu Xing Bing Xue Za Zhi. 2002;23(6):445-448. Chinese.

8. Naldi L. Psoriasis and smoking: links and risks. Psoriasis (Auckl). 2016;6:65-71. doi:10.2147/PTT.S85189

9. Adıșen E, Uzun S, Erduran F, Gürer MA. Prevalence of smoking, alcohol consumption and metabolic syndrome in patients with psoriasis. An Bras Dermatol. 2018;93(2):205-211. doi:10.1590/ abd1806-4841.20186168

10. Richer V, Roubille C, Fleming $\mathrm{P}$, et al. Psoriasis and smoking: a systematic literature review and meta-analysis with qualitative analysis of effect of smoking on psoriasis severity. J Cutan Med Surg. 2016;20(3):221-227. doi:10.1177/1203475415616073

11. Albaghdadi A. Current and under development treatment modalities of psoriasis: a review. Endocr Metab Immune Disord Drug Targets. 2017;17(3):189-199. doi:10.2174/1871530317666170804153751

12. Hancox JG, Sheridan SC, Feldman SR, Fleischer AB. Seasonal variation of dermatologic disease in the USA: a study of office visits from 1990 to 1998. Int J Dermatol. 2004;43(1):6-11. doi:10.1111/ j.1365-4632.2004.01828.x

13. Scala E, Megna M, Amerio P, et al. Patients' demographic and socioeconomic characteristics influence the therapeutic decisionmaking process in psoriasis. PLoS One. 2020;15(8):e0237267. doi:10.1371/journal.pone.0237267

14. Conic RR, Damiani G, Schrom KP, et al. Psoriasis and psoriatic arthritis cardiovascular disease endotypes identified by red blood cell distribution width and mean platelet volume. J Clin Med. 2020;9(1):186. doi:10.3390/jcm9010186

15. Santus P, Rizzi M, Radovanovic D, et al. Psoriasis and respiratory comorbidities: the added value of fraction of exhaled nitric oxide as a new method to detect, evaluate, and monitor psoriatic systemic involvement and therapeutic efficacy. Biomed Res Int. 2018;2018:3140682. doi:10.1155/2018/3140682

16. Damiani G, Franchi C, Pigatto P, et al. Outcomes assessment of hepatitis $\mathrm{C}$ virus-positive psoriatic patients treated using pegylated interferon in combination with ribavirin compared to new direct-acting antiviral agents. World J Hepatol. 2018;10(2):329-336. doi:10.4254/wjh.v10.i2.329

17. Kardeş S. Seasonal variation in the internet searches for psoriasis. Arch Dermatol Res. 2019;311(6):461-467. doi:10.1007/s00403-01901921-0

18. Wu Q, Xu Z, Dan YL, et al. Seasonality and global public interest in psoriasis: an Infodemiology Study. Postgrad Med J. 2020;96 (1133):139-143. doi:10.1136/postgradmedj-2019-136766
19. Balato N, Di Costanzo L, Patruno C, Patrì A, Ayala F. Effect of weather and environmental factors on the clinical course of psoriasis. Occup Environ Med. 2013;70(8):600. doi:10.1136/oemed-2013-101505

20. Pascoe VL, Kimball AB. Seasonal variation of acne and psoriasis: a 3-year study using the physician global assessment severity scale. $J$ Am Acad Dermatol. 2015;73(3):523-525. doi:10.1016/j. jaad.2015.06.001

21. Joint committee for guideline revision. 2016 Chinese guidelines for the management of dyslipidemia in adults. $J$ Geriatr Cardiol. 2018;15(1):1-29. doi:10.11909/j.issn.1671-5411.2018.01.011

22. Liu LS; Writing Group of Chinese Guidelines for the Management of H. 2010 Chinese guidelines for the management of hypertension. Zhonghua Xin Xue Guan Bing Za Zhi. 2011;39(7):579-615.

23. Enamandram M, Kimball AB. Psoriasis epidemiology: the interplay of genes and the environment. $J$ Invest Dermatol. 2013;133 (2):287-289. doi:10.1038/jid.2012.434

24. Hambly R, Kirby B. The relevance of serum vitamin D in psoriasis: a review. Arch Dermatol Res. 2017;309(7):499-517. doi:10.1007/ s00403-017-1751-2

25. Bikle DD. Vitamin D metabolism and function in the skin. Mol Cell Endocrinol. 2011;347(1-2):80-89. doi:10.1016/j.mce.2011.05.017

26. Hu L, Bikle DD, Oda Y. Reciprocal role of vitamin D receptor on $\beta$ catenin regulated keratinocyte proliferation and differentiation. J Steroid Biochem Mol Biol. 2014;144:237-241. doi:10.1016/j. jsbmb.2013.11.002

27. Wolf P, Weger W, Patra V, et al. Desired response to phototherapy versus photoaggravation in psoriasis: what makes the difference? Exp Dermatol. 2016;25(12):937-944. doi:10.1111/exd.13137

28. Johnson-Huang LM, Suarez-Farinas M, Sullivan-Whalen M, Gilleaudeau P, Krueger JG, Lowes MA. Effective narrow-band UVB radiation therapy suppresses the IL-23/IL-17 axis in normalized psoriasis plaques. $J$ Invest Dermatol. 2010;130(11):2654-2663. doi:10.1038/jid.2010.166

29. Walters IB, Ozawa M, Cardinale I, et al. Narrowband (312-nm) UV-B suppresses interferon gamma and interleukin (IL)12 and increases IL-4 transcripts: differential regulation of cytokines at the single-cell level. Arch Dermatol. 2003;139(2):155-161. doi:10.1001/ archderm.139.2.155

30. Piskin G, Koomen CW, Picavet D, Bos JD, Teunissen MB. Ultraviolet-B irradiation decreases IFN-gamma and increases IL-4 expression in psoriatic lesional skin in situ and in cultured dermal $\mathrm{T}$ cells derived from these lesions. Exp Dermatol. 2003;12 (2):172-180. doi:10.1034/j.1600-0625.2003.120208.x

31. Piskin G, Sylva-Steenland RM, Bos JD, Teunissen MB. T cells in psoriatic lesional skin that survive conventional therapy with NB-UVB radiation display reduced IFN-gamma expression. Arch Dermatol Res. 2004;295(12):509-516. doi:10.1007/s00403-004-0460-9

32. Morita A, Werfel T, Stege $H$, et al. Evidence that singlet oxygen-induced human $\mathrm{T}$ helper cell apoptosis is the basic mechanism of ultraviolet-A radiation phototherapy. J Exp Med. 1997;186 (10):1763-1768. doi:10.1084/jem.186.10.1763

33. Ozawa M, Ferenczi K, Kikuchi T, et al. 312-Nanometer ultraviolet B light (narrow-band UVB) induces apoptosis of T cells within psoriatic lesions. J Exp Med. 1999;189(4):711-718. doi:10.1084/jem.189.4.711

34. Coven TR, Burack LH, Gilleaudeau R, Keogh M, Ozawa M, Krueger JG. Narrowband UV-B produces superior clinical and histopathological resolution of moderate-to-severe psoriasis in patients compared with broadband UV-B. Arch Dermatol. 1997;133 (12):1514-1522. doi:10.1001/archderm.1997.03890480034005

35. Krueger JG, Wolfe JT, Nabeya RT, et al. Successful ultraviolet $\mathrm{B}$ treatment of psoriasis is accompanied by a reversal of keratinocyte pathology and by selective depletion of intraepidermal T cells. $J$ Exp Med. 1995;182(6):2057-2068. doi:10.1084/jem.182.6.2057

36. Weatherhead SC, Farr PM, Reynolds NJ. Spectral effects of UV on psoriasis. Photochem Photobiol Sci. 2013;12(1):47-53. doi:10.1039/ C2PP25116G 
37. Weatherhead SC, Farr PM, Jamieson D, et al. Keratinocyte apoptosis in epidermal remodeling and clearance of psoriasis induced by UV radiation. J Invest Dermatol. 2011;131(9):1916-1926. doi:10.1038/ jid.2011.134

38. Pacifico A, Damiani G, Iacovelli P, et al. Photoadaptation to ultraviolet B TL01 in psoriatic patients. J Eur Acad Dermatol Venereol. 2020;34(8):1750-1754. doi:10.1111/jdv.16209

39. Rezzani R, Rodella LF, Favero G, Damiani G, Paganelli C, Reiter RJ. Attenuation of ultraviolet A-induced alterations in NIH3T3 dermal fibroblasts by melatonin. $\mathrm{Br} J$ Dermatol. 2014;170(2):382-391. doi:10.1111/bjd.12622

40. Cravello B, Ferri A. Relationships between skin properties and environmental parameters. Skin Res Technol. 2008;14(2):180-186. doi:10.1111/j.1600-0846.2007.00275.x

41. Egawa M, Oguri M, Kuwahara T, Takahashi M. Effect of exposure of human skin to a dry environment. Skin Res Technol. 2002;8 (4):212-218. doi:10.1034/j.1600-0846.2002.00351.x

42. Egawa M, Tagami H. Comparison of the depth profiles of water and water-binding substances in the stratum corneum determined in vivo by Raman spectroscopy between the cheek and volar forearm skin: effects of age, seasonal changes and artificial forced hydration. Br J Dermatol. 2008;158(2):251-260. doi:10.1111/j.1365-2133.2007.08311.x
43. Denda M, Sato J, Tsuchiya T, Elias PM, Feingold KR. Low humidity stimulates epidermal DNA synthesis and amplifies the hyperproliferative response to barrier disruption: implication for seasonal exacerbations of inflammatory dermatoses. $J$ Invest Dermatol. 1998;111(5):873-878. doi:10.1046/j.1523-1747.1998.00364.x

44. Ryan C, Menter A. Discordance between physician assessment of psoriasis and patient self-assessment: the importance of itch. $\mathrm{Br}$ J Dermatol. 2016;175(1):19-20. doi:10.1111/bjd.14672

45. Singh S, Young P, Armstrong AW. Relationship between psoriasis and metabolic syndrome: a systematic review. $G$ Ital Dermatol Venereol. 2016;151(6):663-677.

46. Damiani G, Bragazzi NL, Garbarino S, et al. Psoriatic and psoriatic arthritis patients with and without jet-lag: does it matter for disease severity scores? Insights and Implications from a Pilot, Prospective Study. Chronobiol Int. 2019;36(12):1733-1740. doi:10.1080/ 07420528.2019.1678629

47. Dickison P, Swain G, Peek JJ, Smith SD. Itching for answers: prevalence and severity of pruritus in psoriasis. Australas $J$ Dermatol. 2018;59(3):206-209. doi:10.1111/ajd.12747

\section{Publish your work in this journal}

Clinical, Cosmetic and Investigational Dermatology is an international, peer-reviewed, open access, online journal that focuses on the latest clinical and experimental research in all aspects of skin disease and cosmetic interventions. This journal is indexed on CAS.
The manuscript management system is completely online and includes a very quick and fair peer-review system, which is all easy to use. Visit http://www.dovepress.com/testimonials.php to read real quotes from published authors. 